\title{
Redes trasatlánticas: el espacio editorial en castellano en el campo cultural contemporáneo
}

La historia de las relaciones socio-culturales que definen la creación del campo literario contemporáneo ha sido escasamente explorada en relación con el nuevo estatuto del escritor profesional en la industria cultural que comienza a desarrollarse a mediados del XIX. La construcción de un escenario de acción socio-cultural implica la buisqueda de agentes dinamizadores, de escenarios de actuación que contribuyan a institucionalizar los intercambios entre sus miembros, y medios emisores que aseguren la pervivencia de los contenidos. Los proyectos editoriales logran articular este circuito de comunicación, sobre todo cuando se persigue la formación de ciudadanos para un modelo de sociedad participante en la gestión civil. El estudio de algunos epistolarios, como el del escritor y politico Victor Balaguer y el editor heterodoxo Salvador Manero, permite avanzar en el conocimiento acerca de la gestión empresarial y político-cultural del mundo de las Letras decimonónicas y la consolidación de redes y de tramas para la difusión de un pensamiento republicano democrático en el ámbito hispánico.

Como se deduce del análisis del actual campo literario en español, el escenario de interlocución editorial ya no puede ser más que internacional, con el desembarco de grandes grupos empresariales como Planeta o Alfaguara en América Latina, puente ineludible para el intercambio y el trasvase de nombres a ambos lados del Atlántico, tarea en la que resulta medular la ayuda de los medios de comunicación aparejados a estas modernas industrias culturales. En este proceso de mundialización editorial, generalizado en el último cuarto del siglo $\mathrm{XX}$, sellos emblemáticos españoles como Salvat o Plaza y Janés han sido absorbidos por las multinacionales Hachette-Matra o Random House Mondadori, como símbolo del diseño de la nueva cartografía de la República de las Letras. Ésta ya sólo puede ser nombrada como 
República Mundial de las Letras, tal como la define Pascale Casanova en su monografía homónima, en la que sigue los esquemas defendidos por Paul Braudel, para quien la Historia ha de razonar por comparación a escala mundial, la única válida (160).

Según expone Casanova, a medida que el espacio literario se autonomiza, esto es, una vez se aparta del dominio de las instituciones políticas y nacionales que ha contribuido a legitimar e instituir, y construye una micro sociedad cosmopolita, e ilustrada, este espacio se sitúa en el ámbito de la globalidad y de la interdependencia que rige los fenómenos económicos ${ }^{1}$. Así, el siglo XIX constituye el observatorio idóneo para analizar el arranque de un proceso que ha conducido, a lo largo de la siguiente centuria, a lo que algunos editores, como André Schiffrin, resumen apocalípticamente como el paso "Del internacionalismo literario a la mundialización comercial”, definido por la transformación de la industria editorial y su asimilación por grupos de empresa de mass media (Casanova 217-27).

Señala Pascale Casanova que la literatura hunde sus raíces en la historia política de los estados: "Para luchar mejor las unas contra las otras, las naciones centrales se han esforzado en promover definiciones y especificidades literarias . . . Las literaturas no son, por tanto, la emanación de una identidad nacional, sino que se crean en la rivalidad (siempre negada) y la lucha literarias, siempre internacionales" (56). Y así explica el desarrollo de la cultura literaria alemana de fines del XVIII en términos de antagonismo político con Francia, la cultura dominante, cuando entra en el espacio literario internacional. Casanova ejemplifica esta autonomización del campo literario en el ámbito latinoamericano. El reconocimiento que la novela del llamado boom ha logrado en el marco de lo que James English define como el capital de la "economy of prestige" no se corresponde con el que tiene en el espacio político internacional (60).

Es en este punto, en el de la especificidad del caso hispanoamericano, en el que surge la discrepancia de Jean Franco con las propuestas del volumen de Casanova, quien ha recibido los parabienes de críticos como Perry Anderson y Terry Eagleton. En su recensión "Epílogo. América Latina en la república de las letras" (2008). Franco cuestiona el énfasis de Casanova por destacar la dimensión autónoma y mundial de los escritores sin atender a su imbricación en la historia política de cada nación, sobre todo cuando analiza el caso del boom latinoamericano de 
los sesenta (513-17). Un reduccionismo que, sin duda, grava con cierta miopía el sugerente ensayo de Casanova, dado el innegable condicionamiento que la historia política tiene no sólo en la configuración del espacio literario de las nuevas naciones americanas, sino en su relación con la antigua metrópoli cultural, Madrid y, a lo largo del XIX, con el nuevo referente estético, la moderna capital literaria, París, a cuyos modelos intentan asimilarse los periféricos, los excéntricos.

Cada escritor, señala Casanova, es depositario de un patrimonio literario y lingüístico nacional, pero su posición depende de cómo acepta este legado (en términos de rechazo, oposición o integración) en otro universo artístico más afín a sus inquietudes; por eso, al caracterizar a un autor, hay que situarlo, al tiempo, según la posición que ocupa en el espacio literario nacional y en el internacional (63). Tal sería el caso de los escritores de la llamada panhispania lingüística, entendida ésta como un espacio de producción y de circulación de textos con sus especificidades estéticas sí, pero también como un espacio transnacional de comunicación artística y comercial. Un espacio tejido por unas redes personales que se fundamentan tanto en afinidades ideológicas y afectivas, como en estrategias para la legitimación profesional y la autoridad social por parte de quienes asisten a la creación y consolidación de nuevas naciones. Nos encontramos en el territorio de lo que Pierre Bourdieu define como campo profesional, con sus reglas y su habitus. Como matiza Roger Chartier, los objetos culturales no son solo un reflejo de la realidad social, sino que tienen una estrecha dependencia y relación con sus propios espacios de producción, difusión y recepción. Tales premisas mueven a Chartier a aplicar la teoría de los campos para analizar el llamado ecosistema del libro, un sistema de agentes interalimentados, interpuestos y encadenados: el autor, el editor, el impresor, el distribuidor, el librero, el crítico y el lector ${ }^{2}$. En suma, parece necesario plantear una historia cultural de la edición atenta a los discursos y a las representaciones sobre el mundo editorial pero, al tiempo, se hace imprescindible el análisis de las prácticas como eje de estudio en un marco transnacional, como se recoge en el volumen editado por Lynn Hunt, The New Cultural History (1989).

Como es sabido, los procesos de independencia consumados en 1824 dieron paso a la liberación del mercado internacional de las nuevas repúblicas americanas. Amparados en la inestabilidad y en la convulsa vida política que caracteriza la centuria en España, los editores y libreros 
franceses y belgas, como los hermanos Garnier, Rosa y Bouret, Mézin, Baudry, Bélin, Colin, Roger y Chernoviz, Baillière, Baudry, Hachette, Morizot, Chaumas, Ollendorff o Dunod y Privat, multiplicaron los catálogos de impresos en castellano. Esta caudalosa producción se destinaba al mercado de las jóvenes repúblicas, nuevas naciones que empezaban a construir sus planes pedagógicos en consonancia con la emergente conciencia nacional y un proyecto literario estrechamente vinculado a aquélla (Fernández, "El monopolio", "En torno", "La editorial Garnier", "Geografías culturales").

La idea de la construcción de los campos culturales como tensiones y luchas abiertas o soterradas por la hegemonía artística es perceptible a lo largo del siglo XIX. En esta centuria en que se fundamentan jurídicamente las leyes que rigen la propiedad intelectual y los convenios internacionales para su defensa; se institucionaliza el estatuto del escritor profesional y se avanza en el asociacionismo de los hombres de letras. Así, la profesionalización del escritor se documenta como un proceso regido por estrategias destinadas a favorecer la autonomía, la autoridad y la legitimidad de una actividad creativa que se defiende como potencialmente útil y con poder formativo. Es la herencia innegable de la imagen del hombre de letras del XVIII; un poder espiritual laico, símbolo de la emancipación y del progreso en la sociedad moderna (Bénichou; Martínez Martín, Vivir de la pluma).

A lo largo del siglo, las exportaciones de impresos desde Francia a Hispanoamérica no cesan de aumentar, sobre todo con destino a México y a Argentina, favorecidas por acontecimientos específicos como la intervención mancomunada entre Inglaterra, Espańa y Francia en 1862, tras la cual las tropas francesas impusieron a Maximiliano I (1864-67) como emperador mexicano. Estas circunstancias históricas, que encerraban aspiraciones de hegemonía política y cultural en cuyo epicentro se hallaba el modelo francés, alentaron los planes de expansión empresarial de editores como Rosa y Bouret, quienes se establecieron en México. La evidente pérdida de influencia intelectual francesa, en contraste con el auge de la cultura anglosajona, animó los proyectos galos para ampliar el escenario de actuación y convocar a otros mediadores culturales no necesariamente hispanohablantes en un proyecto integrador que apelaba a la esencia lingüístico-cultural latina ${ }^{3}$.

Hasta 1890, en que se produce el krach de la edición francesa (Botrel, "La librairie"), no se equilibra la situación editorial; a partir 
de este momento, aumentan las exportaciones de impresos españoles a Hispanoamérica, y se manifiesta cierto proceso de autonomización de la industria cultural en Espańa ${ }^{4}$. A finales del XIX y en las primeras décadas del XX, editoriales como Maucci, Sopena, Sempere, Prometeo, Calleja o Renacimiento asumen los riesgos empresariales de la expansión comercial por Hispanoamérica, en donde sus colegas franceses habían desarrollado un complejo andamiaje de corresponsalías y negocios filiales. La actividad de los editores se vio acompañada de la asesoría de autores relevantes en la conformación del campo hispanoamericano, como Blasco Ibáñez y el editor Sempere o Gómez de la Serna con la casa Calleja o con Biblioteca Nueva, por no hablar del poder editorial ejercido por otros escritores como Gregorio Martínez Sierra.

Las pretensiones de crear un americanismo literario, trasunto de la libertad espiritual que ansiaban las nuevas repúblicas y que las movió a buscar otros modelos culturales y pedagógicos, iban acompasadas con esa búsqueda de referentes que ofrecían, también, las traducciones del francés dirigidas a los nuevos ciudadanos (Suárez de la Torre y Castro; Suárez de la Torre, "L'imprimée au cœur"). Unas traducciones que multiplicaron su efecto al ser reproducidas en la prensa periódica y en otros formatos, producto del mestizaje derivado de las transferencias culturales (Gómez) y de lo que Mary Louise Pratt define como proceso de "autoinvención criolla": la necesidad de crear culturas autónomas y descolonizadas a partir de la adaptación de los discursos europeos sobre América (33). Como señala Casanova, las grandes capitales literarias aplican sistemas de "protección" que les permite conservar un protectorado cultural sobre los escritores periféricos, porque "La traducción es la gran institución de consagración específica del universo literario", fundamental para los "excéntricos" (180), y a la vista está la trascendencia para el llamado boom latinoamericano en el siglo XX de las traducciones al francés.

Juan Valera, viajero impenitente por su labor diplomática, alertó de continuo a los gobiernos y a los escritores espańoles acerca de la importancia de proteger e impulsar el comercio de librería para volver a "influir y prevalecer y hasta ejercer cierta hegemonía en el Nuevo Mundo, sobre todo en el hispano-parlante" (citado en Fernández, "El monopolio" 182). La iniciativa de Valera pretendía sacudir "el yugo intelectual en que los franceses nos tienen", porque "[u]na publicación de libros castellanos para América, hecha en gran escala y con sentido 
común . . contribuiría al esplendor y difusión de nuestra literatura y anularía y sepultaría para siempre en el olvido las malas y groseras ediciones que salen de las prensas de París" $(183,182)$.

En este contexto, parece necesario abordar las relaciones culturales y editoriales entre España e Hispanoamérica en el siglo XIX y en las primeras décadas del XX como primer paso de un proyecto de investigación interdisciplinar con voluntad de futuro5. Tal ha sido la idea que ha motivado la propuesta de este monográfico en torno a los contactos editoriales trasatlánticos como ejes de una identidad cultural. La emergencia de una idea de República Literaria Latinoamericana, en sus orígenes vinculada a un espíritu progresista, laico y republicano, sobre todo a partir de las relaciones establecidas entre los liberales demócratas de ambos lados del Atlántico (López-Ocón, Biografía; Un itinerario). Se trata, pues, de abordar el análisis de la edición cultural como una vía para la creación de un espacio público transnacional, capaz de generar y desarrollar unas estrategias de actuación ideológicas, políticas, identitarias y empresariales. No en vano, el redescubierto espacio comercial de las nuevas repúblicas se avistó como una prometedora Arcadia para los editores más activos de naciones como Francia, Alemania, los Países Bajos o Estados Unidos y, en menor medida, aunque de forma creciente, España.

La historia de las relaciones socio-culturales que definen la creación del campo literario contemporáneo ha sido escasamente explorada en relación con el nuevo estatuto del escritor en la industria cultural que comienza a desarrollarse a mediados del XIX. Tampoco se ha indagado respecto de su papel como impulsor de políticas de asociacionismo corporativo, y como agente de legitimación de estructuras jurídicas, administrativas y empresariales que regulen la República de las Letras como un espacio profesional. La construcción de un escenario de acción socio-cultural implica la búsqueda de agentes dinamizadores, de escenarios de actuación que contribuyan a institucionalizar los intercambios entre sus miembros, así como de medios emisores que aseguren la pervivencia de los contenidos. Los proyectos editoriales permiten articular este circuito de comunicación, sobre todo cuando se persigue la formación de ciudadanos para un modelo de sociedad participante en la gestión civil.

Tal pretensión fundamentó, en el nuevo Estado burgués de Isabel II, propuestas como la Sociedad Literaria (1843-56) de Wenceslao 
Ayguals de Izco, el fundador de la novela popular española de tema contemporáneo, con su célebre trilogía María o la hija de un jornalero (1845-55). La Sociedad Literaria aspiró a crear una República de las Letras integrada por escritores, traductores y periodistas correligionarios, ciudadanos animados por un mismo compromiso cultural e ideológico. La Sociedad Literaria fue concebida como un círculo de lectores a los que se surtía con variados productos de una dinámica factoría de colaboradores y correligionarios, en la tradición formativa del liberalismo decimonónico heredero del espíritu de las Cortes de Cádiz (1810-12).

Ayguals cultivó un cuerpo estable y compacto de lectores a través de un proceso de retroalimentación en el que se ensamblaban todos los intervinientes en la creación y difusión de los escritos acuñados en la Sociedad Literaria; desde las obras de ficción, originales y traducidas, hasta prensa y volúmenes enciclopédicos del corte de La escuela del pueblo. Páginas de enseñanza universal (1852). Los principios del humanitarismo progresista, la democracia y el laicismo, la lucha por las libertades civiles y el combate contra el fanatismo religioso, conforman el ideario de un editor moderno que encuentra en esta profesión la vía para armonizar la acción pública-desarrollada anteriormente como primer alcalde republicano de España, diputado a Cortes y como combatiente anticarlista (Martínez Gallego 45)—con la práctica creativa y la vocación pedagógica. Ayguals, que tenía conocimientos mercantiles, exploró las técnicas publicitarias y de difusión más sofisticadas del momento (Carrillo 37-55). Así, aunó el floreciente sector de la prensa informativa y satírico-festiva (Guindilla, 1842; La Risa, 1843) con la novela por entregas de tema contemporáneo y estilo folletinesco, acomodada a los patrones del sentimentalismo humanitarista de Éugène Sue.

En la factoría de Ayguals, el hermanamiento entre el periodismo y la escritura novelesca constituye el sello editorial por excelencia, derivado de la propia conformación de la empresa. La Sociedad Literaria fue constituida como un consorcio integrado por dos hermanos de Ayguals, Sergio y Demetrio, y un grupo de escritores progresistas, como J. Martínez Villergas, "varios capitalistas, asociados a algunos hombres de letras y los artistas más conocidos” (Martínez Gallego 70). Un auténtico proyecto asociativo que parte de la comunión entre el capital económico y una variada y compacta política editorial; esto es, un preciso sistema de expansión que transciende el ámbito español y construye redes en el espacio europeo (especialmente en Francia) y en territorios ultramarinos como Cuba ${ }^{6}$. 
Ayguals pertenece a la estirpe de los editores que conjugaron el interés comercial, la vocación literaria y el activismo ideológico, como hiciera, años antes, el valenciano Mariano Cabrerizo o su contemporáneo, el madrileño Benito Hortelano. Editores de pensamiento progresista que, tras participar en levantamientos revolucionarios, tuvieron que partir al exilio, uno a Francia, el otro a Hispanoamérica. Ambos personificaron la figura del editor del moderno régimen tipográfico, de quien entiende su profesión casi como un voluntariado cultural y político, como sucederá con otra saga de editores catalanes, la iniciada por López Bernagossi en el siglo XIX, que se prolonga hasta Antonio López Llausás y la conocida Sudamericana de Buenos Aires (López Llovet; Lago Carballo) ${ }^{7}$. De la movilización política de ambos en pro de las libertades y de las vicisitudes arrostradas dan prueba sus memorias; así como de la necesidad de entender el ejercicio profesional en un marco de actuación que no se restrinja al mero interés mercantil y apunte a la creación de redes y de intercambios culturales en un ámbito hispánico ${ }^{8}$. Iniciativas voluntaristas que, impulsadas también por legítimos intereses comerciales, trataron de gestar unas redes sólidas y solidarias; unas redes públicas basadas en afinidades ideológicas y personales que fundamentaran una República Literaria autónoma o, al menos, alternativa.

Hortelano emigró por cuestiones políticas y económicas a Argentina en 1849, donde demostró su dinamismo en un campo cultural en formación. Precedente del novelista y editor, Vicente Blasco Ibáñez, ejemplifica la figura de aquellos editores que pueden asimilarse a un paradigma de exploradores culturales, como los hermanos Salvat Espasa'. Estos jóvenes empresarios-precedidos por otros editores catalanes como Gaspar y Roig, quienes instalaron sucursales de librería en México y en Argentina en la segunda mitad del siglo (Botrel, "Gaspar y Roig")_avistaron el potencial lector de las nuevas repúblicas americanas y apostaron por un conocimiento in situ para trazar lo que Philippe Castellano denomina "geografía de la lectura" (10), paso necesario para abordar nuevos mercados. Este mercado floreciente se presenta como una tierra de promisión para algunos editores, como los Salvat, quienes indagan las posibilidades de esas "zonas de contacto cultural” (Pratt 31) ${ }^{10}$. Su epistolario revela las prácticas comerciales y publicitarias llevadas a cabo, el intento de análisis de las tendencias lectoras y el papel de intermediación cultural ejercido por los editores. Pero las cartas de los Salvat también ilustran acerca de la operatividad de las redes afectivas e ideológicas como plataforma de difusión cultural entre España e Hispanoamérica. 
Escasos son los testimonios personales de editores decimonónicos espańoles, como las memorias de Cabrerizo, Hortelano o las de Julio Nombela, por lo que conjuntos epistolares como el de los hermanos Salvat aportan una luz fundamental sobre las tramas creadas en torno a una red editorial. El epistolario del editor, librero y representante dramático, Salvador Manero, al escritor y político Víctor Balaguer así lo demuestran. Las sesenta cartas remitidas entre 1863 y 1871 permiten entrever la interrelación entre la gestión del mundo de las Letras y la posible gestación de grupos de influencia en la maquinaria del Estado para la difusión de un pensamiento democrático ${ }^{11}$. En este intercambio de correspondencia, se traslucen las redes construidas en torno a las afinidades ideológico-culturales de un empresario editorial de notable formación y un destacado político, Víctor Balaguer. Esta relación se remonta, al menos, a la década de 1860, un período histórico en España en que se intensifican y se consolidan las periódicas conspiraciones y revueltas de los sectores progresistas y republicanos.

Este es el escenario en que se sitúa el estudio de Aurélie Vialette, "Peligros de un obrero lector: filántropos, editores y proletariado en la España del siglo XIX”, atento a las estrategias ensayadas por Salvador Manero y un grupo heterogéneo de escritores por conformar un cuerpo de lectores entre los estratos populares de la moderna ciudad industrial, representada en este caso por Barcelona ${ }^{12}$. Como se deduce del epistolario de Manero y de Balaguer, la actividad editorial se interpreta como un potencial mecanismo de actuación en la esfera pública, mediante la interacción de tres elementos fundamentales: la prensa, el teatro y una línea editorial definida que permita coordinar las expectativas del lectorado afín y las producciones de los escritores. En definitiva, se trata de un proyecto alimentado por un espíritu asociativo de corte ideológico-cultural. En el caso de la empresa de Salvador Manero, como sucede con otros editores heterodoxos del siglo XIX (Fernández, "Los 'soldados'”), a menudo radicados en Barcelona, la estructura sociocomercial permite una suerte de criptoasociacionismo y de apostolado ideológico más o menos directo que sortea los riesgos de la acción política directa, controlada y perseguida legalmente. De ahí que sea posible hablar de una red ideológico-cultural trabada en torno a Salvador Manero (Fernández, "Los 'soldados"” 133), donde se entrelazan escritores y periodistas del activismo republicano, dispuestos a ejercer la tutela cultural de las nuevas masas urbanas. Una red que se canaliza bajo la 
forma, socialmente aceptada, de un filantropismo pedagógico que, en ocasiones, puede encubrir fórmulas de control para que el obrero no sea un agente cultural autónomo, en palabras de Vialette, quien sigue las propuestas de Žižek en Violence (2008).

La búsqueda de nuevos lectores entre los contingentes de trabajadores urbanos alienta la creación de algunos volúmenes misceláneos como El libro del obrero (1862). Este heterogéneo y enciclopédico tomo, compuesto por escritores de perfil tan diverso como Josefa Massanés, Manuel Angelón, Ceferino Tresserra, Juan Mañé y Flaquer, Antonio Altadill o el propio Víctor Balaguer, y editado por Manero, es interpretado por Vialette como un espacio discursivo para la alfabetización y el control socio-moral del trabajador en el espacio urbano. Imbuido de cierto espíritu filantrópico, la edición de este volumen se inserta en un acto de dominación cultural de las sociedades musicales populares desarrolladas desde 1845, en el que aparece embarcado Manero. La vía educativa como fórmula de conciliación social, tan explorada por el ambiguo humanitarismo sentimental de las novelas folletinescas, alienta tras las páginas de El libro del obrero, un proyecto editorial que traza una sólida red de correspondencias con la línea seguida por La Sociedad Literaria de Ayguals de Izco y el liberalismo progresista decimonónico.

El lento pero paulatino incremento del número de lectores y la consolidación y el auge de la prensa escrita; la experimentación con formatos editoriales y narrativos vinculados con el medio periodístico (la novela folletinesca y por entregas); el constante temor a la censura y la búsqueda de solidaridades afectivo-ideológicas como parte del proyecto editorial, constituyen el intertexto del epistolario de Salvador Manero a Balaguer. Los detalles específicos relacionados con la publicación del periódico La Montaña de Montserrat (1868-69); el celo que ha de demostrar el editor responsable de un periódico para evitar los artículos inmorales o de contenido revolucionario; en definiva, el estatuto múltiple de un editor comprometido cultural e ideológicamente, como Manero, evidencian la consolidación de la figura de un editor moderno que conjuga la misión del empresario cultural, el editor periodístico, con la del político activo.

Al tiempo, Manero, como precedente de los agentes literarios actuales, gestiona el pago por el derecho de las representaciones de las obras de Balaguer, así como da consejos para la mejor difusión de volúmenes como la Historia de Cataluña (1860-63). El epistolario de Manero se convierte en un memorial reivindicativo dirigido al amigo y 
colaborador, Balaguer, que logra desarrollar una sólida y estable carrera política en Madrid gracias al apoyo de un colectivo de empresarios catalanes. En el turbulento y revolucionario año de 1868, Manero desgrana el ideario político que parecen compartir ambos corresponsales, y que evidencia el compromiso de algunos hombres de Letras que, como sucederá con Balaguer, terminan por adaptarse a ese posiblismo pactista que, salvando las distancias, más tarde acuñaría Emilio Castelar como única vía para la integración y participación del republicanismo revolucionario en las estructuras restauracionistas ${ }^{13}$. Manero repite de continuo su pesar por el descrédito que cae sobre la Revolución de 1868 y sus logros; las divisiones internas, el desconocimiento de los políticos de los movimientos populares y la falta de comunicación en los partidos. En la carta del 15 de abril de 1869 (Balaguer, Epistolari de Victor Balaguer 1990, 6900767), la declaración es palmaria: el único camino posible es "una república de orden, conservadora, sin hablar de república; no debemos ir mendigando", porque "la revolución está muerta", corrobora en otra posterior $(21-\mathrm{V}-1869,6901151)$.

Manero desgrana en este epistolario su credo político de ciudadano comprometido con su momento histórico: defensa de los derechos y libertades individuales; abolición de las quintas, de la esclavitud y de la pena de muerte; regulación del matrimonio civil; libertad de cultos y de imprenta. Un ideario que articulará el discurso de numerosos escritores progresistas. Así, registra las convulsiones políticas y los desórdenes públicos en clave de deterioro de la República de las Letras, y de su principal estructura, la red editorial: "pronto verá V. como no exagero; las imprentas cerradas y los autores sin encontrar quien les tome una cuartilla, me darán la razon desgraciadamente" (29-X-1869, Balaguer, Epistolari de Victor Balaguer 1990, 6903005).

La inseguridad en el espacio urbano, que permea los propios domicilios de los ciudadanos con visibilidad política, suspende publicaciones y envíos, y exacerba las críticas de Manero contra el ministro de Fomento, el escritor José de Echegaray, a quien imputa desatención a los asuntos de gobierno de las Letras. La presión ejercida por el editor en su amigo político revela la necesidad de buscar una cobertura para el negocio que le ayude a sobrellevar las vicisitudes del momento. Manero acomete la edición de una obra dedicada a la masonería porque se le insinuó la necesidad de dar a conocer tal sociedad: "Por mi parte haré lo que pueda para que la publicación esté al alcance de todo el mundo" (17-III-1870, Balaguer, Epistolari de Victor Balaguer 1992, 7000283). 
Y para su difusión solicita a Balaguer, vinculado a la Orden, "facilitarme relaciones" para mover muchos ejemplares, no sin antes preguntar por la posible sanción o peligro derivado de editar tales obras ${ }^{14}$. Balaguer colabora en la creación y extensión de este entramado editorial que aspira a ser una red difusora de doctrina y autoridad entre un cuerpo de lectores y de correligionarios articulada a partir de las afinidades que emparentan a un colectivo ${ }^{15}$. Estas afinidades pueden llegar a configurar una comunidad de base emocional como las enunciadas por Max Weber (33), entrelazada por una identidad imaginaria en torno a unas creencias y cierto espíritu de resistencia frente a un entorno adverso o, al menos, no afecto.

Salvador Manero, en una carta fechada el 12 de agosto de 1871 (Balaguer, Epistolari de Victor Balaguer, 7102572), insiste en la necesidad de regular el comercio de impresos con los territorios de Ultramar. Asimismo, destaca el interés de algunos editores-como el madrileño Antonio San Martín, otro heterodoxo-por analizar y explorar el potencial mercado trasatlántico, merced a los viajes oficiales de Balaguer, como se confirma en la redactada el 17 de septiembre de 1870 (Balaguer, Epistolari de Victor Balaguer 1992, 7000889). La ofensiva de los franceses, belgas y holandeses, a los que se le sumarán los norteamericanos, a lo largo del siglo XIX, alertará a los españoles acerca de la necesidad de mirar al mercado hispanoamericano, un espacio comercial, pero también un espacio para el intercambio, la difusión y discusión de ideas y conocimientos.

Fechas como el centenario de 1892 o el Congreso Económico Social Hispanoamericano (1900) constituyen puntos de encuentro para la expresión de un espíritu hispanoamericanista impulsado por el liberalismo democrático decimonónico que deviene fuerza motriz del regeneracionismo ${ }^{16}$. Las reclamaciones de una política exterior que impulse y defienda los tratados y convenciones internacionales para el comercio editorial, reforme los aranceles o rebaje el precio del papel, mueve a iniciativas corporativistas de editores y literatos, como la creación de la Unión Ibero-Americana, aprovechando la Conmemoración del IV Centenario de la llegada de Colón, y la creación de sociedades profesionales de libreros y editores (Martínez Martín, Martínez Rus y Sánchez García). Las primeras décadas del siglo registran una actividad incesante porque, como señala Gustavo Gili, "todos ven en las Repúblicas sudamericanas la tierra de promisión para sus sueños de ambición 
y de riqueza” (7). Y concluye el representante de los editores españoles, "El libro es el elemento colonizador por excelencia. Pueblo que exporta libros es indudablemente un pueblo rico y próspero".

Vicente Blasco Ibáñez ya se había implicado en actividades editoriales con clara vocación de activismo socio-político y literario, como se evidencia con la fundación de La Propaganda Democrática (1892) _ junto con Miguel Sennent-, con el diario El Pueblo y su Biblioteca Popular (1897). Blasco ofrece el perfil de un hombre de acción revestido de la función de escritor: los foros periodísticos y editoriales actúan de amplificadores de su campaña pública en defensa de los ideales democráticos y republicanos, de clara inspiración doceañista (Fernández, "Las Cortes” 16-34). En la década de 1890, Blasco se vincula al proyecto editorial de Sempere-que mutará en Prometeo en 1914, con su novela Los argonautas - y al de la editorial Española-Americana. El novelista emprenderá su propia odisea americana en un formato editorial: como impulsor del comercio de libros, pero sobre todo como promotor de su propia obra, que adapta al nuevo mundo cultural descubierto, dando paso al llamado período americano, iniciado en 1910 con Argentina y sus grandezas.

Javier Lluch-Prats analiza esta etapa de "autogestión de un escritor-editor" en "La antesala del triunfo de un editor y escritor profesional: Vicente Blasco Ibáñez en Argentina (1909-1914)"; una demostración de cómo un escritor puede convertirse en asunto de estado, auspiciado por las presidencias argentinas (251). Lluch-Prats evidencia cómo un hombre de letras puede ejercer de agente cultural trasatlántico, como también hicieran Amado Nervo, Rubén Darío o Ricardo Palma, creando redes y tramas culturales, flujos editoriales y transferencias literarias que se inician a partir de la colaboración en la prensa hispanoamericana. Y nuevamente, son los epistolarios los que permiten conocer las tramas internas que componen esa República Mundial de las Letras trasatlánticas. Como el que Blasco Ibáñez dirige al periodista Carlos Silva Vildósola de El Mercurio (1900) de Chile. En estas páginas se registra cómo le encomienda las gestiones para la edición chilena de algunas de sus obras; cómo le detalla las condiciones económicas para la comercialización de Los cuatro jinetes del Apocalipsis en su país; o cómo le insta a que promocione su novela y las de Prometeo en la prensa, al tiempo que le informa de la propuesta de la Casa editorial Flammarion de París para abordar una Colección de Novelas Españolas ${ }^{17}$. 
El principio democratizador de la cultura, la formación de ciudadano críticos y conscientes y la búsqueda de nuevos públicos, son los pilares de la propuesta editorial de Sempere y Blasco Ibáńez, como señala Lluch-Prats. Ambos auscultaron las posibilidades de un campo cultural en formación y potencialmente provechoso en términos empresariales, pero sobre todo fecundo para la transferencia cultural, como demostraron las coediciones hispano-argentinas que llevaron a cabo. En este espíritu se funda también la iniciativa de otro escritor de acción, Eduardo Zamacois, promotor de empresas culturales vinculadas a una red empresarial de corte republicano-progresista que perfiló un proyecto editorial adaptado a la nueva sociedad de masas, como se señala en "Eduardo Zamacois: empresario cultural y viajante de literatura" de Ana Cabello .

Curtido en la publicación de prensa galante y seguidor de un tardonaturalismo escandaloso, Zamacois diseñó una estrategia de difusión cultural enraizada en la tradición satírico-festiva de la prensa republicana progresista del XIX, pero alentada por un espíritu empresarial moderno, en donde prensa, literatura y cine terminan por confluir en una propuesta novedosa destinada al público hispanoamericano. El diseño del catálogo de Cosmópolis se vincula a una línea editorial comprometida con la defensa de unos principios ideológicos afines al republicanismo revolucionario. En estas coordenadas ha de entenderse su propósito de recuperar a Galdós, autor bisagra en el cambio de modelos estéticos en el período de entresiglos pero símbolo, al tiempo, de cierta evolución hacia la figura del escritor comprometido con las circunstancias sociales y revestido del simbolismo de las figuras públicas (Fernández, "Galdós y el banquero republicano"). El proyecto de las traducciones de sus obras al francés puede enmarcarse en esos intercambios y transferencias basados en las afinidades afectivo-ideológicas que crearon estrechas redes colaborativas entre activistas políticos en el exilio francés, hombres de letras y empresarios comprometidos, como los que se vincularon a las iniciativas de Zamacois.

Y precisamente en ese modelo del escritor activo, reconocido públicamente en su dimensión literaria e ideológica, como Blasco Ibáñez y, en menor medida, el propio Zamacois, se inspira éste cuando diseña un espectáculo performativo para promocionar a los escritores españoles en Hispanoamérica, como expone Cabello. La imbricación de su labor como conferenciante con la emisión de documentales en torno a figuras de las Letras en el escenario de un teatro emparenta 
con la nueva figura del comisionista de libros, del viajante de literatura que fue Zamacois. El escritor viaja revestido del capital simbólico que supone el catálogo de la editorial Renacimiento, en un momento en que el mercado editorial hispanoamericano se abría generosamente hacia España y la presencia de las plumas españolas en los grandes diarios ganaba posiciones. Agentes activos en el proceso de conquistar nuevos espacios para la difusión de las ideas, para la participación en el debate público, los editores modernos como Blasco Ibánez o Zamacois se dirigen a los nuevos consumidores de bienes culturales, ya sea desde los escenarios, ya desde la prensa, ya desde la alianza estratégica con sectores financieros que permitieran insertar el negocio literario en la nueva economía de mercado, como se analiza en "Unir los números a las letras': la intervención del escritor en el sector editorial en el período de entresiglos (XIX/XX)" de Christine Rivalan-Guégo.

Zamacois y Blasco Ibáñez defendieron un proyecto socio-cultural enraizado en la exploración de las nuevas capacidades comunicativas favorecidas por la influencia de la prensa periódica y su lectorado fiel, en el que el escritor actúa de gozne entre un modelo de editor financiero (publisher) y el gestor del fondo editorial (editor), esto es, quien define el espiritu de su colección (Ollivero). Las colecciones de novela breve, tan vinculadas al sector de la prensa y a su sistema de distribución y aparición periódica, fueron el campo de experimentación de los nuevos formatos, formas y contenidos de una oferta ficcional que se deseaba extensiva y masiva. Una producción editorial que, al tiempo que aseguraba la autonomía de sus creadores, conllevaba un subyacente ideario socio-educativo y una inserción de la literatura en los debates más actuales del momento. Tales proyectos generaron nuevos modelos de relación profesional entre los autores, nuevos hábitos de producción y de consumo y cierta conciencia, alentada desde las propias colecciones, acerca de que los lectores integraban una comunidad periférica respecto del canon de la ortodoxia moral y literaria, lo que favoreció la creación de unos canales fluidos de comunicación e interacción entre los creadores y su público. Renacimiento, CALPE, Compañía Iberoamericana de Publicaciones (CIAP), exploran la diversificación en la inversión de capitales, la fórmula de compromiso con los autores emparentados por un similar proyecto socio-literario, como se evidencia con la CIAP, vinculada a la Casa de Banca Rothschild por la vía de su representante en 
España, Ignacio Bauer. La CIAP y su nueva política económica supuso una reordenación y autonomización del campo literario en español, en el primer tercio del XX.

El mercado hispanoamericano formaba parte medular de este proyecto dirigido por un consejo editorial letrado que concertaba el interés por la rentabilidad económica, la innovación creativa y la difusión literaria. Las editoriales, así, configuraban un nuevo espacio de sociabilidad cultural, reforzado, como era el caso de la CIAP, por banquetes, homenajes o tertulias, que constituían escenarios simbólicos de intercambio y de parentesco estético-empresarial. La búsqueda de localizaciones urbanas que actuaran como ejes de articulación de lo que podríamos llamar una "comunidad imaginada" de las Letras (Anderson), con sus especificidades y divergencias, se complementa con la multiplicación de foros de opinión y de creación: las revistas literarias. Estas se formulan como un punto de encuentro y de expresión extraterritorial de una modernidad que, desde un punto de enunciación local—la sede de la revista-, aspira a la interlocución transnacional en un campo literario construido a partir de la disidencia frente al reduccionismo partidista. Tal es el caso de la gestión de la Revista Azul (1894-96) de A. Gutiérrez Nájera y de la Revista Moderna de México (1903-11) de Jesús E. Valenzuela, como se expone en el estudio de Gustavo Jiménez Aguirre sobre "La casa azul y la cofradía del arte: dos revistas mexicanas en el imaginario intercontinental de la 'raza latina' (1894-1903)".

Cuando la Academia Mexicana excluye a los poetas liberales de sus filas, nace la propuesta de una gran casa de espíritu transnacional inserta en el debate en torno a la identidad cultural de América desde una posición que podríamos llamar paratópica (Maingueneau); esto es, desde un punto de enunciación local se crea un lugar autónomo con una vocación estética universalista como principio rector de un imaginario fundado en la raza latina. Una raza latina producto de la diversidad y el necesario cruzamiento; una interdiscursividad que ha de huir de la imitación, revitalizarse con el contacto con las novedades europeas sin olvidar la herencia cultural española. Como señala Jiménez Aguirre, en la Revista Azul la valoración de la obra literaria se fundamenta en su capacidad de productividad intertextual, en su poder de apropiación y reelaboración estéticas. Porque, como indica E. Said, "la historia de la cultura no es otra que la historia de préstamos culturales. Las culturas no son impermeables . . . La cultura no es nunca cuestión 
de propiedad, de tomar y prestar con garantías y avales, sino más bien de apropiaciones, experiencias comunes, e interdependencias de toda clase entre diferentes culturas" (337).

Las cada vez más estrechas relaciones entre Francia y México, ya mencionadas, fundamentalmente a partir de 1860, alimentan la noción panlatina, con México como frontera geocultural frente al imperialismo estadounidense, según las Conferencias de la Paz de la Haya (1899). Asimismo, en este proyecto de modernidad literaria transoceánica también es posible detectar los ecos del pensamiento de Emilio Castelar y su ideal de República de las Letras, alimentada en sus continuos viajes de exilio y por su constante colaboración trasatlántica. Pero la noción de comunidad literaria propiamente hispánica alcanza dimensiones utópicas con las propuestas idealistas del Ariel (1900) de José Enrique Rodó y enlaza con el modelo historiográfico de una comunidad literaria hispánica desarrollado por el dominicano Pedro Henríquez Ureña en torno a las tesis regeneracionistas sobre el Renacimiento español, entendido como eje de la modernidad espańola. Tales son las tesis del análisis de historia intelectual abordado por Leonardo Martínez Carrizales en "El modelo historiográfico de la comunidad literaria hispánica: derivas del arielismo y el regeneracionismo en Pedro Henríquez Ureña”.

Ariel circuló entre las comunidades de intelectuales, favorecida por el grupo de regeneracionistas de la Universidad de Oviedo, que encabezaban Clarín y Rafael Altamira. Una difusión que habla de una red editorial y de publicistas embarcados en la propagación de un espíritu que reclama el liderazgo cultural espańol por la vía de situar la obra de Rodó en el panorama geocultural trasatlántico. El espacio universitario como escenario para la reforma social, impulsada por la figura de los intelectuales vinculados a la remodelación de la educación pública; la aspiración a una sociedad letrada que superara las tensiones de su horizonte de enunciación y asumiera su capacidad directora; la discusión sobre la integridad de la América hispana y su posición en el relato de la cultura moderna "en un sistema internacional convulsionado por nuevos liderazgos en conflicto", son los pilares de este Proyecto sociocultural, como señala Martínez Carrizales (324).

Los proyectos intelectuales para afianzar un canon de la modernidad hispánica germinaron en forma de proclamas, revistas, editoriales, en cafés y tertulias como una manifestación material y simbólica de una praxis colectiva que pretende legitimar un proyecto en el campo 
literario. Las revistas, entendidas y analizadas como "textos colectivos" enunciadores de una determinada política cultural (citado en Rodríguez Martín, 337), constituyen excelentes plataformas para desbrozar cómo se crean las tramas y los contextos culturales, sus prácticas y discursos, y cómo se intentan articular a partir de la legitimación del escritor, del intelectual como interlocutor en los debates en torno al canon de la modernidad española, como se desprende del estudio de Carmen Rodríguez Martín, "Entre dos orillas: Guillermo de Torre y los avatares de un Proteo intelectual".

Así, la figura de Guillermo de Torre permite vislumbrar, a partir de su vinculación con La Gaceta Literaria (1927-31) y la polémica del meridiano intelectual de Hispanoamérica, la actividad como mediador cultural trasatlántico a partir de su colaboración en esta revista y en la bonaerense Martín Fierro (1924-27) pero, sobre todo, a raíz de su viaje a Argentina en 1927. Será a partir de su exilio en 1939, cuando su propuesta de discurso y acción se materialice a través de un compromiso con proyectos editoriales sustentados en cierta red solidaria entre los escritores, artistas y editores sometidos a un proceso de adaptación y transculturación a causa del exilio o la emigración, y que aspiraban a insertarse en el campo cultural argentino e hispanoamericano. Editoriales como Sudamericana, Losada, Espasa-Calpe Argentina, Emecé Editores o Poseidón simbolizan no sólo los años de esplendor del mercado de la edición argentina (1938-55), cuando los empresarios monopolizaron la publicación mundial en castellano, sino la aportación a esta "época de oro" de la diáspora de editores y escritores que conformaron la Espańa Peregrina tras la Guerra Civil (Diego 91, 104, 112). No obstante, no es posible entender y calibrar esta aportación sin recordar los flujos de editores y escritores de décadas precedentes para la consolidación de una República de las Letras hispánica, trasatlántica, progresista y democrática, tal como se intenta argumentar en este Dossier Crítico.

\author{
Centro de Ciencias Humanas y Sociales \\ Consejo Superior de Investigaciones Científicas \\ (CCHS-CSIC, Madrid, Spain)
}

\title{
NOTAS
}

${ }^{1}$ Pascale Casanova adopta como rasgos definidores de esa micro sociedad el modelo de la "Internacional intelectual" que reclamaba Valèry Larbaud en los ańos veinte del siglo pasado (226-27). 
${ }^{2}$ Una propuesta que se materializa en algunos trabajos como Pasando página de Sergio Vila-Sanjuán. La Historia de la edición y de la lectura en España. 1472-1914 de Infantes, López y Botrel es la mejor muestra de cómo aplicar esta integradora mirada metodológica.

${ }^{3}$ Los proyectos político-culturales europeos que pretendían la integración de las nuevas repúblicas del centro y del sur de América se han articulado en torno a propuestas como el iberoamericanismo, el panlatinismo, el latinoamericanismo y el hispanoamericanismo. Cada una de ellas trasluce un escenario de enunciación y unas directrices geo-culturales diversas. Acerca de la propuesta panlatina, impulsada durante el reinado de Napoleón III y encabezada por Michel Chevalier a partir de sus viajes a América, a instancias del ministro Thiers, y aprovechada para sus propios intereses estratégicos por Italia, vid. Phelan y los volúmenes colectivos Ideas en torno a Latinoamérica. Ya se sabe del sustrato masónico como eje articulador de una trama conspiratoria que favoreció las luchas independentistas americanas y los intentos democráticos en España a lo largo del XIX. Frente a estas perspectivas de fraternización político-cultural a partir de un pasado europeo común, surgieron propuestas de clara reivindicación indigenistas, como las abanderadas por M. González Prada en Perú, a tal efecto, puede consultarse Ward y Tauzin.

${ }^{4}$ Larraz; Martínez Rus; Suárez de la Torre y Castro; Suárez de la Torre, Constructores y "L'imprimée au cœur".

${ }^{5}$ La concepción de este monográfico se inscribe en el marco de los Proyectos de Investigación de I+D+i HUM2007-63608/FILO y FFI 2010-17273 del Gobierno de España.

${ }^{6}$ Zavala desmenuza las relaciones personales y editoriales entre Ayguals y Sue, a quien el escritor espańol tradujo, con extraordinario éxito, y de quien logró una carta-preámbulo para su novela María o la hija de un jornalero. Vid. también la clásica monografía de R. Benítez, Ideología del folletín español. Wenceslao Ayguals de Izco (1801-1873).

${ }^{7}$ Acerca de la evolución del concepto de "editor" en el siglo XIX, vid. Martínez Martín, "La edición artesanal" (32-52).

${ }^{8}$ Ménguez Rodríguez analiza las memorias escritas por estos dos editores. A su juicio, representan el binomio que, según Pierre Bourdieu, define al editor moderno. De este modo, escribe Bourdieu: "Ya que el libro, objeto de doble cara, económica y simbólica, es a la vez mercancía y significación, el editor es también un personaje doble, que debe conciliar el arte y el dinero, el amor a la literatura y la búsqueda del beneficio" (259-60).

${ }^{9}$ Mary Louise Pratt toma la expresión “exploratrice sociale” de Marie-Claire HoockDemarle, para denominar a las viajeras que, como Flora Tristán, relataron sus experiencias en viajes que tenían una dimensión de conocimiento de las condiciones sociales y culturales del otro (286-304). 
${ }^{10}$ Asimismo, Pratt denomina "zonas de contacto" a "los espacios sociales donde culturas dispares se encuentran, chocan y se enfrentan, a menudo dentro de relaciones altamente asimétricas de dominación y subordinación, tales como el colonialismo, la esclavitud, o sus consecuencias" (31). En palabras de Pratt, "Una perspectiva 'de contacto' destaca que los individuos que están en esa situación se constituyen en y a través de su relación mutua", es decir, "en términos de presencia simultánea, de interacción, de conceptos y prácticas entrelazadas" (34).

${ }^{11}$ En la Biblioteca Museo de Víctor Balaguer, en Vilanova i la Geltrú, se conservan 99 cartas (1863-77) de la editorial de Salvador Manero a Balaguer, pero no la respuesta del escritor quien, en ocasiones, realiza alguna anotación marginal en las que le dirige aquél. Cfr. el catálogo epistolar en Balaguer, Epistolari de Victor Balaguer.

${ }^{12}$ A pesar de la relevante trayectoria de la casa editorial de Salvador Manero, a quien sucedió su hijo, su establecimiento no aparece en el estudio de Manuel Llanas. Acerca de la trayectoria de este editor, puede consultarse Fernández ("Los 'soldados'” 133-34).

${ }^{13}$ El editor Salvador Manero, al igual que Balaguer, evoluciona desde la posición de republicano revolucionario hacia la fórmula de un defensor de la monarquía democrática propuesta por Prim y materializada en la figura de Amadeo de Saboya, tal como declara en su carta de 7 de abril de 1869. El epistolario del editor Salvador Manero a Víctor Balaguer se encuentra en el archivo de la Biblioteca Museo Víctor Balaguer de Vilanova i la Geltrú (Barcelona). La descripción incompleta del contenido de estas cartas se recoge en los volúmenes Epistolari de Victor Balaguer. Las citas textuales de las cartastranscritas literalmente-proceden de los manuscritos originales, de los que aportamos la fecha de redacción, que es la base de clasificación en el propio Archivo.

14 "Cuando estuve en esa el año pasado se me habló de la necesidad que había de alguna obra que tratara de francmasonería, encargué una y hoy la tengo en prensa; sé que V. sabe algo de esta sociedad" (17-III-1870, Balaguer, Epistolari de Victor Balaguer 1990, 7000283). En 1870, Manero, que había preguntado si era "conveniente no poner el pié de imprenta" para evitar posibles sanciones legales (17-III-1870), edita el Francmasonería: ritual del aprendiz de masón de Jean-Marie Ragon.

${ }^{15}$ Acerca de las editoriales como centros productores de conocimiento y configuradores de prácticas culturales a través de una política interna bien definida, ver Sinclair.

${ }^{16}$ Acerca de su incidencia en las relaciones culturales y en el hispanoamericanismo finisecular, así como de la fuerza motriz de este espíritu en el regeneracionismo, vid. García-Montón; López-Ocón, Biografía; y Mainer.

${ }^{17}$ Las siete cartas, dirigidas desde París y Niza entre el 25 de abril de 1916 y el 11 de febrero de 1918, se conservan en la Sala Cervantes de la Biblioteca Nacional de Espańa (Madrid), bajo la signatura Ms $20272^{4}$. 


\section{OBRAS CITADAS}

Anderson, Benedict. Comunidades imaginadas. Reflexiones sobre el origen y la difusión del nacionalismo. Trad. Eduardo L. Suárez. México, DF: Fondo de Cultura Económica, 1993. Impreso.

Balaguer, Víctor. Epistolari de Víctor Balaguer. Aproximació a un Catàleg (1842-1868). Ed. Montserrat Comas. Biblioteca Museo Víctor Balaguer: Vilanova i la Geltrú, 1986. Impreso.

—. Epistolari de Víctor Balaguer: Aproximació a un Catàleg (1869). Ed. Montserrat Comas. Biblioteca Museo Víctor Balaguer: Vilanova i la Geltrú, 1990. Impreso.

Epistolari de Victor Balaguer: Aproximació a un Catàleg (1870). Ed. Montserrat Comas. Biblioteca Museo Víctor Balaguer: Vilanova i la Geltrú, 1992. Impreso.

Bénichou, Paul. La coronación del escritor. Ensayo sobre el advenimiento de un poder espiritual laico en la Francia moderna. Trad. Aurelio Garzón del Camino. México, DF: Fondo de Cultura Económica, 1981. Impreso.

Benítez, Rubén. Ideología del folletín español. Wenceslao Ayguals de Izco (1801-1873). Madrid: José Porrúa Turanzas, 1979. Impreso.

Botrel, Jean-François. "La librairie 'espagnole' en France au XIXe siècle”. Le Commerce de la Librairie en France au XIXe siècle. 1789-1914. Ed. Jean-Yves Mollier. Paris: IMEC Éditions/Éditions de la Maison des Sciences de l'Homme, 1997. 287-97. Impreso.

"Gaspar y Roig et le rêve américain des éditeurs espagnols (1845-1861)”. Le livre dans la France méridionale et l'Europe méditerranéenne (XVIe-XXe siècles). Ed. Roland Andréani, et al. Montpellier: U Paul Valéry, 2003. 269-85. Impreso.

Bourdieu, Pierre. Las reglas del arte. Génesis y estructura del campo literario. Trad. Thomas Kauf. Barcelona: Anagrama, 1995. Impreso.

Cabrerizo, Mariano de. Memorias de mis vicisitudes politicas desde 1820 a 1836. Valencia: D. Mariano de Cabrerizo, 1854. Impreso.

Carrillo, Víctor. "El periódico Guindilla (1842-1843) de W. Ayguals de Izco y la evolución de las ideas republicano-federales en España”. La prensa de la revolución liberal. Ed. Alberto Gil Novales. Madrid: U Complutense de Madrid. 1983. 37-55. Impreso.

Casanova, Pascale. La República mundial de las Letras. Trad. Jaime Zulaika. Barcelona: Anagrama, 2001. Impreso.

Castellano, Philippe, ed. Dos editores de Barcelona por América Latina. Fernando y Santiago Salvat Espasa. Epistolario bilingüe 1912-1924, 1918 y 1923. Madrid: Iberoamericana; Frankfurt am Main: Vervuert, 2010. Impreso.

Chartier, Roger. El mundo como representación: Estudios sobre historia cultural. Barcelona: Gedisa, 2002. Impreso.

Diego, José Luis de, ed. Editores y politicas editoriales en Argentina, 1880-2000. México, DF: Fondo de Cultura Económica, 2006. Impreso. 
Fernández, Pura. "Las Cortes de Cádiz en la Historia de la Revolución Española". Las Cortes de Cádiz. Historia de la Revolución Española. Ed. Vicente Blasco Ibáñez y Pura Fernández. Cádiz: Servicio de Publicaciones de la Diputación de Cádiz, 2007. 9-66. Impreso.

"La editorial Garnier y la difusión del patrimonio bibliográfico en castellano en el siglo XIX”. Tès philiès táde dôma. Miscelánea léxica en memoria de Conchita Serrano. Ed. Departamento de Filología Grecolatina del CSIC. Madrid: Consejo Superior de Investigaciones Científicas, 1999. 603-12. Impreso.

"En torno a la edición fraudulenta de impresos españoles en Francia: la Convención Literaria Hispano-Francesa (1853)”. Estudios de Literatura Española de los siglos XIX y XX. Ed. José C. de Torres Martínez \& Cecilia García Anton. Madrid: Consejo Superior de Investigaciones Científicas, 1998. 200-09. Impreso.

"Galdós y el banquero republicano Adolfo Calzado: el estreno de Electra en París (1904)”. Bulletin of Spanish Studies 87.1 (2010): 51-68. Impreso.

"Geografías culturales: Miradas, espacios y redes de las escritoras hispanoamericanas en el siglo XIX”. Miradas sobre España. Ed. Facundo Tomás Ferré, Isabel Justo \& Sofía Barrón. Madrid: Anthropos, 2011. 153-70. Impreso.

"El monopolio del mercado internacional de impresos en castellano en el siglo XIX: Francia, España y 'la ruta' de Hispanoamérica”. Bulletin Hispanique 100 (1998): 165-90. Impreso.

"Los 'soldados' de la República Literaria y la edición heterodoxa en el siglo XIX". Prensa, impresos, lectura en el mundo ibérico e iberoamericano contemporáneo. Ed. Jean-Michel Desvois. Bordeaux: P U de Bordeaux, 2005. 125-36. Impreso.

Franco, Jean, "Epílogo. América Latina en la república de las letras”. Intelectuales y poder. Ensayos en torno a la república de las letras en el Perú e Hispanoamérica (siglos $X V I-X X)$. Ed. Carlos Aguirre \& Carmen McEvoy. Lima: Institut Français d'Études Andines, 2008. 511-23. Impreso.

García-Montón, Isabel. "El Congreso Social y Económico Hispanoamericano de 1900: un movimiento del hispanomericanismo modernizador". Revista Complutense de Historia de América 25 (1999): 281-94. Impreso.

Gili, Gustavo. Proyecto de Asociación de los Amigos del Libro. Cámara del Libro Español. Barcelona: s.e., 1917. Impreso.

Gómez Alvarez, Cristina. "La transición entre los siglos XVIII y XIX: la difusión de las obras francesas en Nueva España". Impressions du Mexique et de France. Impresiones de México y de Francia. Ed. Lisa Andries \& Laura Beatriz Suárez de la Torre. Paris: Maison des Sciences de l'Homme, 2009. 45-65. Impreso.

Hortelano, Benito. Memorias de Benito Hortelano. Madrid: Espasa-Calpe, 1936. Impreso.

Hunt, Lynn Avery, ed. The New Cultural History. Berkeley: U of California P, 1989. Impreso.

Infantes, Víctor, François López y Jean-François Botrel, eds. Historia de la edición y de la lectura en España. 1472-1914. Madrid: Fundación Germán Sánchez Ruipérez, 2003. Impreso. 
Lago Carballo, Antonio. "Antonio López Llausás y la Editorial Sudamericana”. Un viaje de ida y vuelta. La edición española e iberoamericana (1936-1975). Ed. Antonio Lago Carballo \& Nicanor Gómez-Villegas. Madrid: Siruela, 2006. 195-202. Impreso.

Larraz, Fernando. Una historia transatlántica del libro. Relaciones editoriales entre España y América Latina (1936-1950). Gijón: Trea, 2010. Impreso.

Llanas, Manuel. Història de l'edició a Catalunya. El segle XIX. Barcelona: Gremi d'Editors de Catalunya, 2002. Impreso.

López Llovet, Gloria. Sudamericana. Antonio López Llausás, un editor con los pies en la tierra. Buenos Aires: Dunken, 2004. Impreso.

López-Ocón, Leoncio. Biografía de la "América": Una crónica hispano-americana del liberalismo democrático español (1857-1886). Madrid: Consejo Superior de Investigaciones Científicas, 1987. Impreso.

Un itinerario por el Madrid isabelino de 1859 del liberal colombiano José María Samper. Madrid: Instituto de Estudios Madrileños, 1987. Impreso.

Mainer, José-Carlos. "Un capítulo regeneracionista: el hispanoamericanismo, 18921923". La doma de la quimera. Ensayos sobre nacionalismo y cultura en España. Madrid: Iberoamericana, 2004. 125-80. Impreso.

Maingueneau, Dominique. Le discours littéraire. Paratopie et scéne d'enonciation. Paris: Armand Colin, 2004. Impreso.

Martínez Gallego, Francesc. "Democracia y república en la España isabelina. El caso de Ayguals de Izco”. Ed. Manuel Chust. Federalismo y cuestión federal en España. Castelló de la Plana: U Jaume I, 2004. 45-90. Impreso.

Martínez Martín, Jesús A. "La edición artesanal y la construcción del mercado”. Historia de la edición en España 1836-1936. Ed. Jesús A. Martínez Martín. Madrid: Marcial Pons, 2001. 29-71. Impreso.

- Vivir de la pluma: La profesionalización del escritor, 1836-1936. Madrid: Marcial Pons, 2009. Impreso.

Martínez Martín, Jesús A., Ana Martínez Rus y Raquel Sánchez García. Los patronos del libro. Las asociaciones corporativas de editores y libreros, 1900-1936. Gijón: Trea, 2004. Impreso.

Martínez Rus, Ana. "La industria editorial española ante los mercados americanos del libro. 1892-1936”. Hispania 62.3 (2002): 1021-58. Impreso.

Ménguez Rodríguez, Felipe. "Las dos caras de Jano: Notas sobre las Memorias de Benito Hortelano y Mariano de Cabrerizo". El legado de Mnemosyne: Las escrituras del yo a través del tiempo. Ed. Antonio Castillo Gómez \& Verónica Sierra Blas. Gijón: Trea, 2007. 259-72. Impreso.

Nombela, Julio. Impresiones y recuerdos. Ed. Jorge Campos. Madrid: Tebas, 1976. Impreso.

Ollivero, Isabelle. Linvention de la Collection: De la diffusion de la littérature et des savoirs à la formation du citoyen au XIX siècle. Paris: Éditions de la Maison des Sciences de l'Homme, 1999. Impreso.

Phelan, John L. "Panlatinismo, la intervención francesa en México y el origen de la idea de Latinoamérica”. Latinoamérica. Anuario de Estudios Latinos 2 (1969): 119-41. Impreso. 
Pratt, Mary Louise. Ojos imperiales. Literatura de viajes y transculturación. Trad. Ofelia Castillo. México, DF: Fondo de Cultura Económica, 2010. Impreso.

Ragon, Jean-Marie. Francmasonería: ritual del aprendiz masón. . . Trad. S de G. Barcelona: Imprenta de Salvador Manero, 1873. $2^{a}$ ed. Impreso.

Said, Edward. Cultura e imperialismo. Trad. Nora Catelli. Barcelona: Anagrama, 2004. Impreso.

Sinclair, Alison. Trafficking Knowledge in Early Twentieth-Century Spain. Centres of Exchange and Cultural Imaginaries. Woodbridge: Tamesis, 2009. Impreso.

Suárez de la Torre, Laura, ed. Constructores de un cambio cultural: impresores-editores y libreros en la ciudad de México, 1830-1855. México, DF: Instituto Mora, 2003. Impreso.

"L'imprimée au cour de la construction savante de l'identité: la librairie française au Mexique, une sensibilité transférée?” Archéologie du sentiment en Amérique latine. L'identité entre mémoire et histoire, XIXe-XXIe siècles. Ed. Denis Rolland, et al. Paris: L'Harmattan, 2005. 19-36. Impreso.

Suárez de la Torre, Laura, y Miguel Ángel Castro, eds. Empresa y cultura en tinta y papel (1800-1860). México, DF: Instituto Mora, 2001. Impreso.

Tauzin, Isabelle, ed. Manuel González Prada: escritor de dos mundos. Lima: Instituto Francés de Estudios Andinos, 2006. Impreso.

Vila-Sanjuán, Sergio. Pasando página. Autores y editores en la España democrática. Barcelona: Destino, 2003. Impreso.

Ward, Thomas Butler. La anarquía inmanentista de Manuel González Prada. Nueva York: Peter Lang, 1998. Impreso.

Weber, Max. Economía y sociedad. Esbozo de sociología comprensiva. Ed. Johannes Winckelmann. Vol 1. México, DF: Fondo de Cultura Económica, 1944. Impreso.

Zavala, Iris M. "Socialismo y literatura: Ayguals de Izco y la novela espańola". Revista de Occidente 80 (1969): 167-88. Impreso.

Zea, Leopoldo, ed. Ideas en torno a Latinoamérica. México. 2 vols. Mexico, DF: UNAM, 1986. Impreso.

Palabras claves: relaciones trasatlánticas, historia cultural de la edición, hispanoamericanismo, república mundial de las letras.

Fecha de recepción: 13 marzo 2011

Fecha de aceptación: 5 mayo 2011 